Universidade Tecnológica Federal do Paraná - UTFPR

Campus Ponta Grossa - Paraná - Brasil

ISSN: 1981-3686 / v. 03, n. 02: p.81-96, 2009
Revista Brasileira deTecnologia

Agroindustrial

\title{
ANÁLISE DOS SURTOS NOTIFICADOS DE DOENÇAS TRANSMITIDAS POR ALIMENTOS NO ESTADO DE SÃO PAULO ENTRE 1995 E 2008
}

\section{ANALYSIS OF NOTIFIED OUTBREAKS OF FOOD-BORNE DISEASES IN THE STATE OF SÃO PAULO BETWEEN 1995 AND 2008}

\author{
Laurí Mayer ${ }^{1}$; Wladimir Padilha da Silva ${ }^{2}$ \\ ${ }^{1}$ Universidade Federal de Pelotas - UFPEL - Pelotas - Brasil - laurimayer@gmail.com \\ ${ }^{2}$ Universidade Federal de Pelotas - UFPEL - Pelotas - Brasil - silvawp@ufpel.edu.br
}

\begin{abstract}
Resumo
O consumo de alimentos e água contaminados com microrganismos ou substâncias químicas pode provocar doenças transmitidas por alimentos (DTAs). Neste trabalho foram analisados os surtos de DTAs notificados no Estado de São Paulo entre 1995 e 2008 a partir da base de dados do Centro de Vigilância Epidemiológica de SP. Os resultados mostraram que neste período foram notificados 3.115 surtos, com 99.689 doentes e 44 mortes. O maior número de surtos ocorreu em residências $(28,2 \%)$, creches $(11,6 \%)$, restaurantes $(10,1 \%)$, escolas $(6,4 \%)$ e festas $(4,3 \%)$, sendo que em $22,2 \%$ dos surtos o local de ocorrência não foi identificado. Os alimentos mistos foram os mais envolvidos (25\%), seguidos pelo contato pessoa-pessoa $(6,4 \%)$, água $(4,9 \%)$, farináceos $(3,2 \%)$, carnes vermelhas $(2,5 \%)$, pescado $(2,3 \%)$ e ovos e produtos de ovos $(1,9 \%)$, sendo que em $47 \%$ dos surtos o alimento responsável não foi identificado. Nas creches e escolas o vírus da hepatite A $e$ rotavírus foram os microrganismos mais envolvidos, causando juntos 47,6\% e 39,7\% dos surtos, respectivamente. Nas festas, restaurantes e residências Salmonella sp. foi o principal microrganismo, causando 29,1\%, 10,8\% e 6,2\% dos surtos, respectivamente. Dos 44 óbitos confirmados, 34\% dos surtos foram em residências e em 25\% desses surtos o agente etiológico não foi identificado. Dos principais microrganismos envolvidos, Salmonella sp. apresentou o maior declínio do número de surtos a partir de 2001, acumulando uma queda de 84\% até 2008, sugerindo que a população está mais consciente em relação aos cuidados no preparo e armazenamento dos alimentos.
\end{abstract}

Palavras-chave: alimentos; surtos; hepatite A; Salmonella sp.; rotavírus.

\section{Introdução}

As doenças transmitidas por alimentos (DTAs) são conhecidas desde tempos remotos. Já em 2000 AC., Moisés determinou algumas leis sobre métodos de preparo dos alimentos (incluindo aqueles que se podia comer e os que se deveria rejeitar), bem como a importância da limpeza das mãos antes de ingerir os alimentos (BRASIL, 2005). Entretanto, foi somente no século XIX, com as 
descobertas de Louis Pasteur, que ficou estabelecido a relação entre microrganismos e a deterioração dos alimentos, incluindo a capacidade destes de causarem doença.

As DTAs são causadas pela ingestão de alimentos ou água contaminados com agentes biológicos ou químicos, como por exemplo, bactérias, vírus, príons, parasitas, toxinas, agrotóxicos, produtos químicos e metais pesados. Entretanto, a grande maioria dos surtos de DTAs são causados por vírus e bactérias (JAY, 2005). Há mais de 250 tipos de DTAs descritas, sendo que algumas doenças são consideradas emergentes, como a síndrome hemolítica urêmica (SHU), síndrome de Creutzfeld-Jacob e campilobacteriose (BRASIL, 2005).

Nos Estados Unidos, um estudo feito por MEAD et al (1999) estimou em 76 milhões o número de pessoas afetadas anualmente em decorrência de DTAs, causando 325 mil hospitalizações e 5 mil mortes, com um custo estimado de 30 milhões de dólares. Já o número de casos que foram notificados é bem menor. Em 2007, por exemplo, foram notificados ao CDC (Center for Disease Control and Prevention) 1.097 surtos com 21.183 casos (UNITED STATES, 2009). No Brasil os dados são mais escassos, mas dados do Ministério da Saúde mostram que de 1999 a 2004 ocorreram 3.737 surtos com 73.517 casos (BRASIL, 2005), o que resultou em uma média de 623 surtos e 12.253 casos por ano no país.

De fato, o número de surtos notificados de DTAs representa apenas a ponta de um iceberg, se comparado com o total de ocorrências (FORSYTHE, 2000). Em um estudo feito na Inglaterra constatou-se que para cada caso notificado, existem outros 136 casos não notificados na comunidade, como mostra a Figura 1.

Figura 1. Pirâmide que estima a proporção entre casos notificados e não notificados de DTAs.

1

caso

notificado

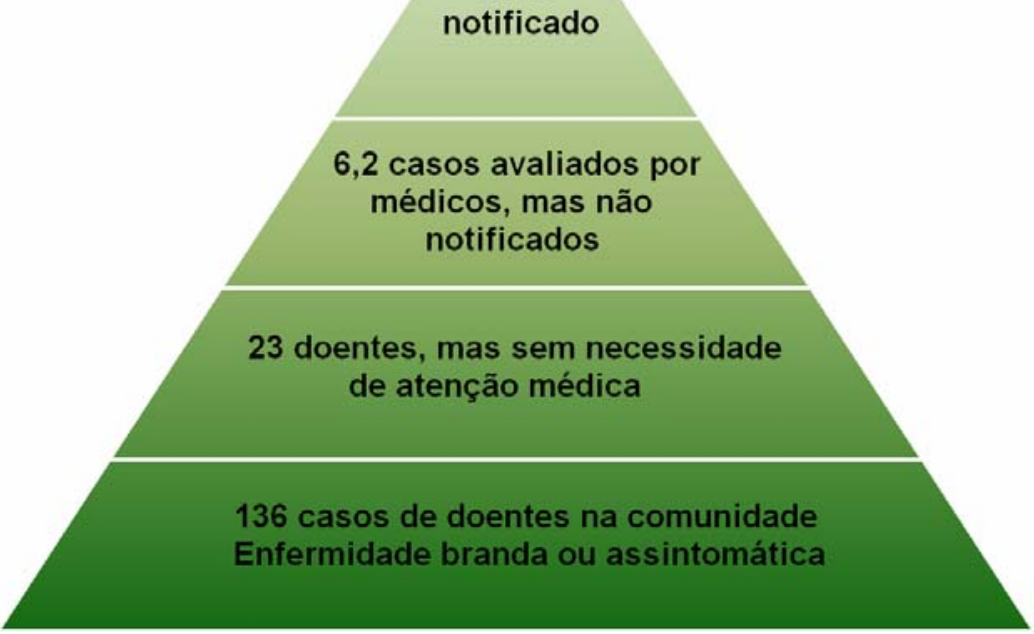

Fonte: adaptado de WLEELER et al, 1999. 
A ingestão de alimentos contaminados com microrganismos patogênicos se dá, muitas vezes, pelo fato de que eles apresentam aspecto, odor e sabor normais e o consumidor não está devidamente esclarecido ou consciente dos perigos envolvidos. Este fato também dificulta a investigação dos surtos notificados, pois o consumidor não consegue identificar qual alimento poderia estar contaminado em suas últimas refeições (FORSYTHE, 2000).

Este trabalho objetivou traçar um perfil dos surtos de doenças transmitidas por alimentos notificados no Estado de São Paulo de 1995 a 2008, identificando o número de surtos, número de pessoas afetadas, número de óbitos, principais agentes etiológicos e tipos de alimentos envolvidos, principais locais de ocorrência e segundo diferentes microrganismos, variação do número de surtos ao longo do período analisado dos principais agentes etiológicos responsáveis, porcentagem de pessoas doentes em relação ao número de pessoas expostas segundo diferentes microrganismos, além da exposição de outros resultados complementares.

\section{Material e Métodos}

Os dados foram obtidos a partir da base de dados do Centro de Vigilância Epidemiológica “Prof. Alexandre Vranjac” da Secretaria Estadual de Saúde do Estado de São Paulo (CVE-SP), e referem-se ao período de 1995 a 2008.

Os dados referentes aos surtos de DTAs notificados ao CVE-SP foram processados e condensados no programa Excel for Windows versão 12.0 (Microsoft@) e os resultados discriminados por data (ano), número de surtos, número de casos (pessoas doentes), agente etiológico, local de ocorrência, fonte de transmissão (alimentos envolvidos) e número de óbitos. Os resultados referentes ao local de ocorrência dos surtos e fonte de transmissão englobam somente dados a partir de 1999, excluído o ano 2007. Os dados anteriores a 1999 não contém estas informações, e para o ano de 2007 as mesmas ainda não foram disponibilizados pelo CVE-SP.

\section{Resultados e Discussão}

Com base nos dados compilados, entre 1995 e 2008 foram notificados no Estado de São Paulo 3.115 surtos de doenças transmitidas por alimentos, com 99.689 casos (pessoas doentes). O número de surtos notificados, bem como o número de casos apresentou ampla variação nos 14 anos pesquisados (Fig. 2). De maneira geral, observou-se uma proporcionalidade entre número de casos e número de surtos. Porém, esta proporcionalidade não ocorreu em todos os períodos. Por exemplo, de 2002 a 2004 o número de surtos diminuiu 25,2\% (302 para 226) mas o número de casos aumentou 267,6\% (5.678 para 15.197), e a partir de 2006 o número de surtos praticamente se 
estabilizou (queda de apenas 6,7\%) mas o número de surtos diminuiu 56,7\% (11.082 para 4.797). A Figura 2 destaca ainda que em uma considerável parcela dos surtos, não foi possível identificar o agente etiológico responsável.

Figura 2. Número de surtos notificados de DTAs e número de pessoas afetadas (doentes) no Estado de São Paulo entre 1995 e 2008.

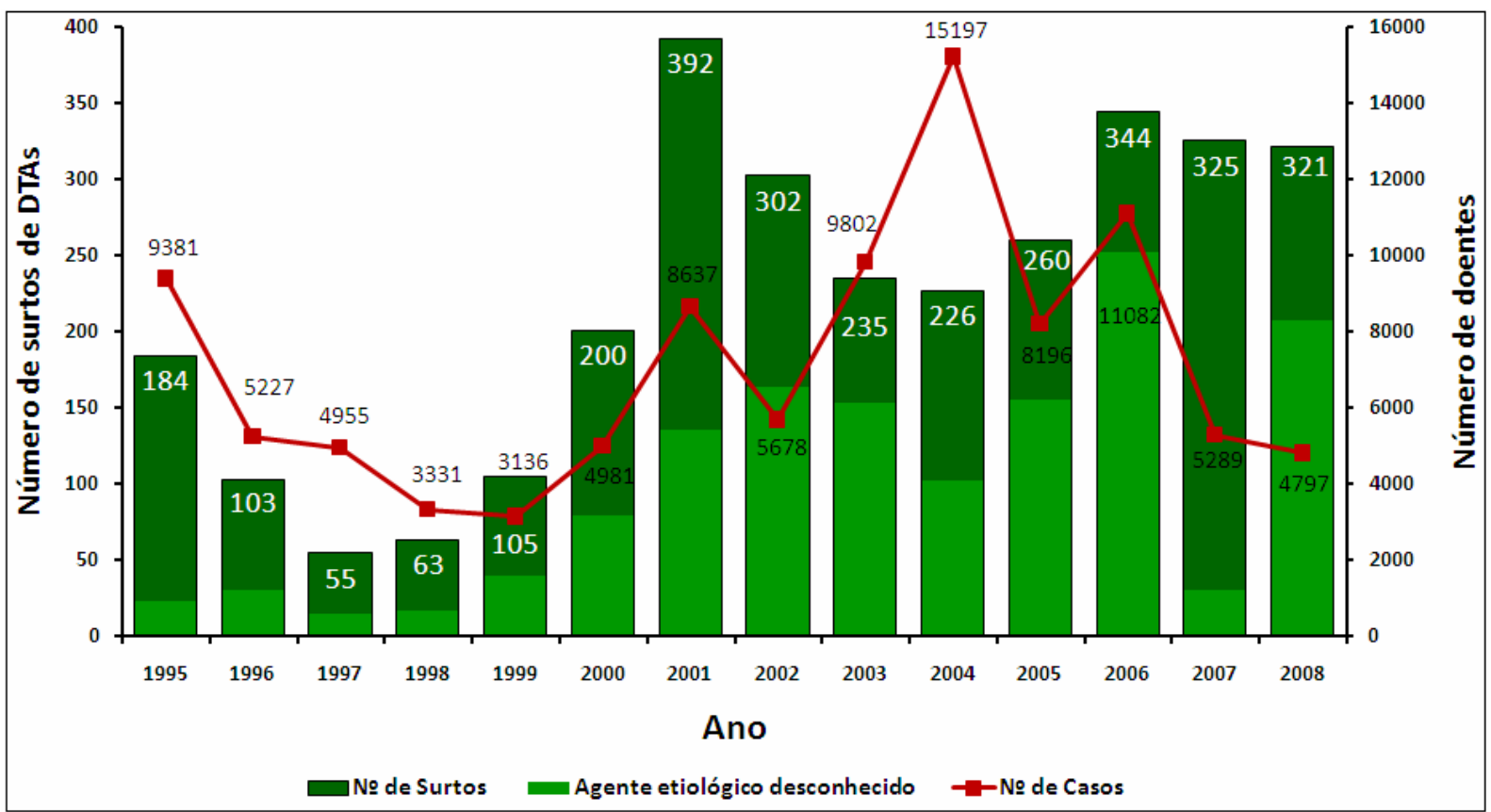

O Estado de São Paulo atingiu em 2007 uma população estimada de 40 milhões de habitantes (IBGE, 2009). No mesmo ano foram notificados ao CVE-SP 5.289 casos de DTAs, o que representa apenas 0,013\% da população. Entretanto, se for feito uma analogia com o estudo de WHEELER et al (1999), em que na Inglaterra para cada surto notificado há outros 136 não notificados, poder-se-ia estimar que 1,8\% da população de SP é afetada por alguma doença transmitida por alimentos anualmente. Considerando-se ainda que no Brasil o atendimento à saúde para a maioria da população sabidamente sofre problemas de toda ordem, e que com isso muitas pessoas com sintomas e/ou doenças brandas não busca ou não consegue atendimento médico, podese supor que esta porcentagem é provavelmente superior.

Em relação ao local de ocorrência dos surtos de DTAs no Estado de São Paulo, os dados mostraram que a maior parte (28,2\%) ocorreu em residências, e que estas juntamente com as creches e os restaurantes foram responsáveis por praticamente a metade (49,9\%) dos surtos (Fig. 3). Se for considerado que uma parcela dos surtos que não possuem local de ocorrência identificado ocorreram em um dos três locais mencionados, é possível afirmar que estes locais mencionados corresponderam por mais da metade dos surtos. A Figura 3 mostra ainda que em 22,2\% dos surtos o local de ocorrência não foi identificado. Este fato decorre de vários motivos, mas principalmente 
porque (devido ao estilo de vida atual), as pessoas tendem a alimentar-se em vários locais diferentes em um único dia, e quando os sintomas de DTA aparecem e um possível surto é investigado, não é mais possível fazer uma relação entre o surto e local onde o alimento foi comprado e/ou consumido.

Figura 3. Porcentagem de surtos notificados de DTAs no Estado de São Paulo entre 1999 e 2008 (excluído o ano 2007) segundo o local de ocorrência.

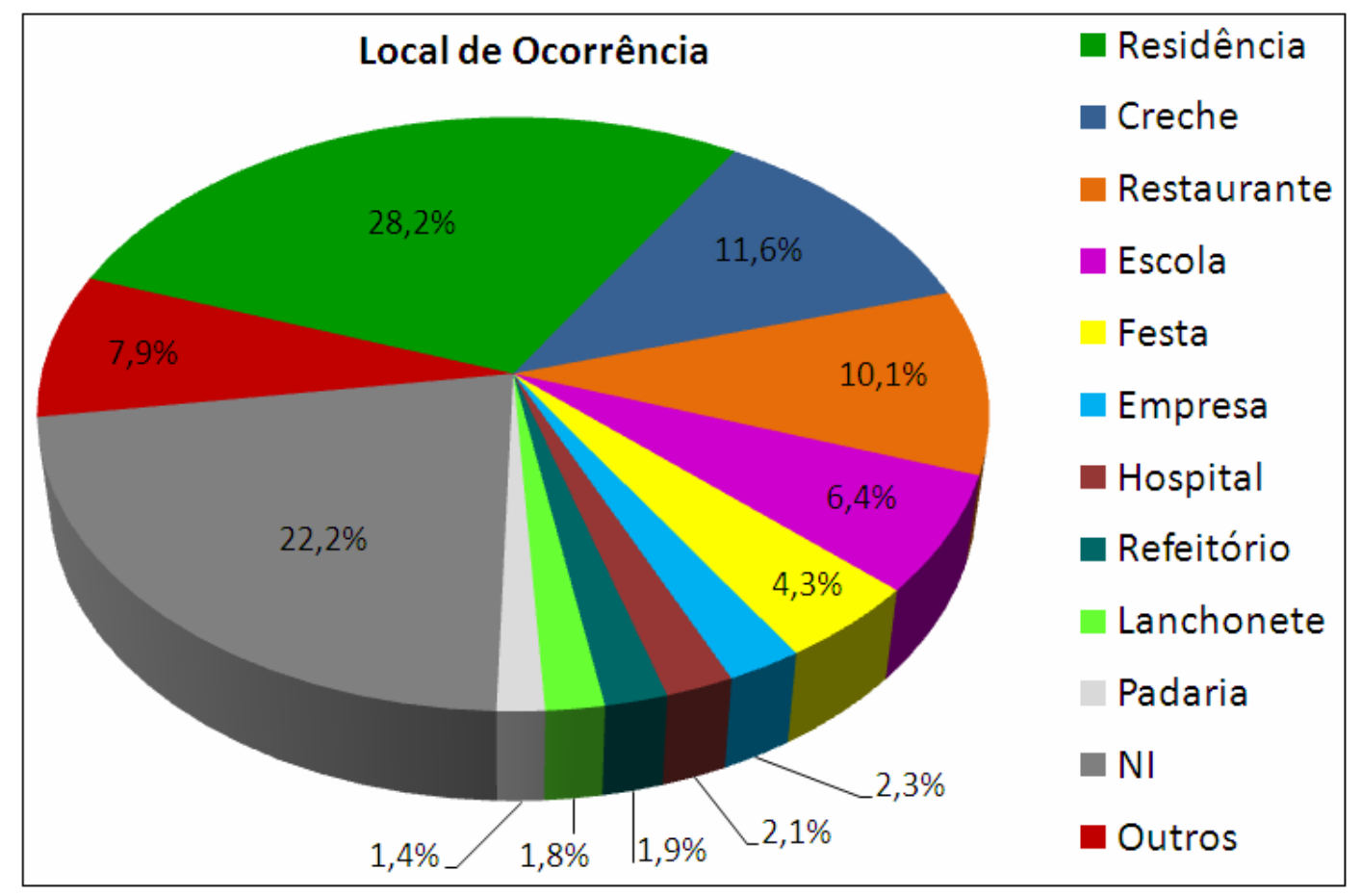

Os tipos de alimentos envolvidos nos surtos foram bastante amplos, e para sintetizar e melhorar a apresentação dos resultados eles foram reunidos em grupos correlacionados. Os dados mostraram que o grupo de alimentos mais envolvidos são os alimentos mistos, responsáveis por 25\% dos surtos (Fig. 4). Nestes casos, o agente etiológico causador do surto foi isolado de mais de um alimento, geralmente pertencentes a uma mesma refeição, ou de alimentos compostos, (ex. lanches), onde não foi possível identificar a origem (matéria-prima) do(s) microrganismo(s) envolvido(s) no surto. Por outro lado, na maior parte dos surtos (47\%) o alimento envolvido não foi identificado. Na maior parte dos surtos isso é devido ao alimento já ter sido todo consumido ou descartado, impossibilitando as análises microbiológicas posteriores, ou mesmo porque o local onde o alimento foi comprado e/ou consumido permanece desconhecido. As transmissões pessoa-pessoa foram responsáveis por 6,4\% dos surtos e as duas principais doenças transmitidas por este meio foram rotavírus (45\%) e hepatite A $(34,7 \%)$. A água foi responsável por 4,9\% dos surtos e as principais doenças transmitidas por ela foram a hepatite A (20,5\%) e coliformes (11,1\%), sendo que em 51\% desses surtos o microrganismo não foi identificado. 
Figura 4. Porcentagem de surtos notificados de DTAs no Estado de São Paulo entre 1999 e 2008 (excluído o ano 2007) segundo o tipo de alimento envolvido.

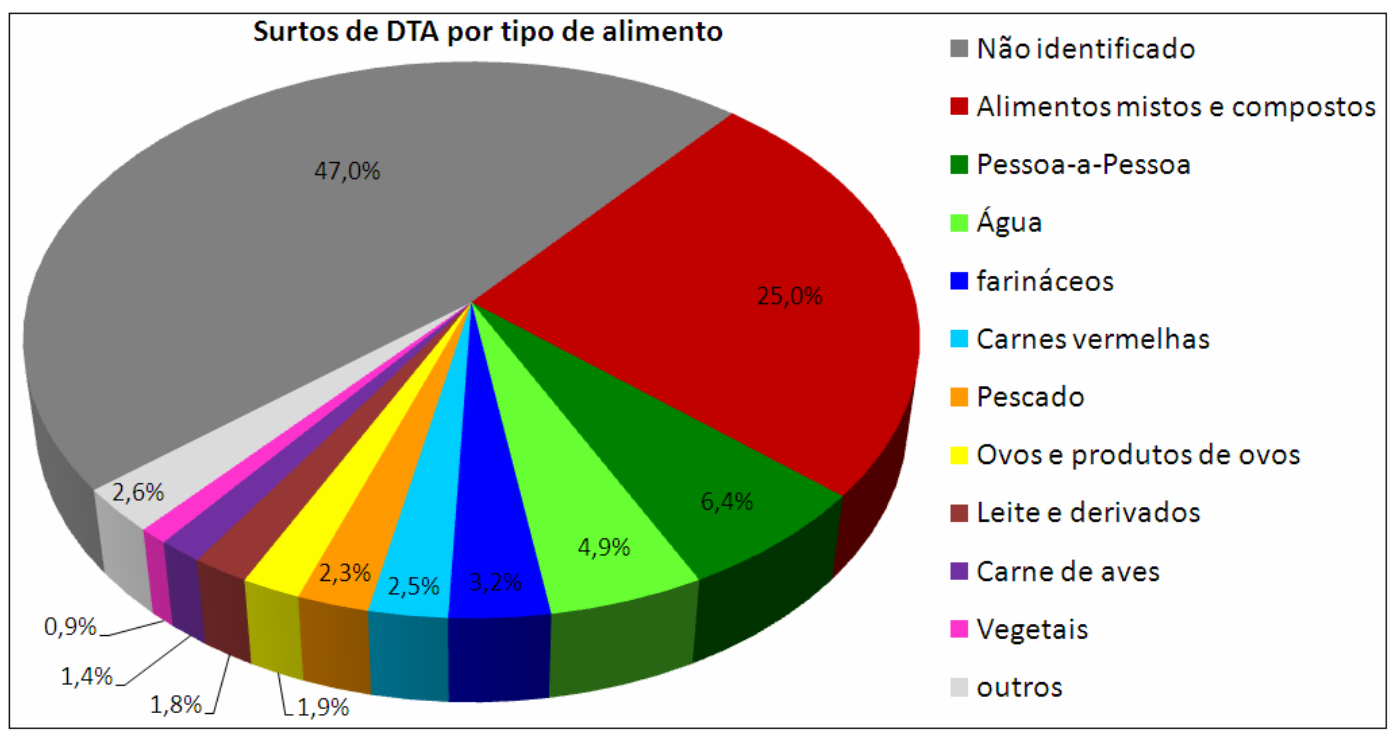

Em relação aos agentes etiológicos causadores das DTAs, os dados mostraram que o vírus da hepatite A foi o agente etiológico responsável mais envolvido, correspondendo a 17,7\% dos surtos, e que em praticamente metade dos casos (49,7\%) o agente etiológico responsável não foi identificado (Fig. 5A). Salmonella sp. e rotavírus apareceram em seguida com 9,6\% e 8,7\% dos surtos, respectivamente. Quando a análise dos surtos de DTAs foi feita segundo locais de ocorrência específicos, a porcentagem de participação de cada microrganismo modificou-se consideravelmente.

Dos diferentes locais de ocorrência dos surtos, foi nas residências onde a maior porcentagem (72,2\%) do agente etiológico responsável não foi identificado (Fig. 5B). Os microrganismos mais freqüentemente envolvidos foram Salmonella sp. (6,2\%), rotavírus (4,6\%), vírus da hepatite A $(4,2 \%)$ e Staphylococcus coagulase $+(2,4 \%)$. Comparativamente no Rio Grande do Sul, que foi um dos primeiros Estados a implantar a vigilância das doenças transmitidas por alimentos (dados desde 1980), as residências também foram o principal local de ocorrência dos surtos (41,7\%), seguido do comércio (22,3\%) e indústria (10,9\%) (RIO GRANDE DO SUL, 2006).

Nas creches merece destaque a alta incidência de hepatite A (39,4\%) e rotavírus (8,2\%), que juntos representaram quase a metade dos surtos nestes locais (Fig. 5C). A porcentagem dos surtos causados por estes dois agentes virais em creches (47,6\%) foi maior em relação a qualquer outro local de ocorrência de surtos de DTAs no Estado de São Paulo no período estudado. Padrão semelhante foi observado nas escolas, onde a hepatite A e o rotavírus também foram responsáveis pela maior parte dos surtos, representando $34,4 \%$ e $8,2 \%$, respectivamente (Fig. 5E). Mundialmente, acredita-se que as gastrenterites virais sejam a segunda doença mais freqüente, perdendo somente para os resfriados comuns (JAY, 2005). Ainda segundo JAY (2005), nos surtos 
de DTAs virais, o vírus da hepatite A é o microrganismo mais freqüente. A veiculação de vírus por alimentos e água é passiva, uma vez que só se multiplicam no interior de células vivas. Por outro lado, esses agentes podem ser concentrados até 900 vezes por alguns mariscos e moluscos, uma vez que capturam seu alimento por filtração (GERBA \& GOYAL, 1978). Para o vírus da hepatite A, a rota fecal-oral é o modo de transmissão mais comum, e os moluscos provenientes de águas poluídas, crus ou parcialmente cozidos, são os alimentos mais envolvidos (JAY, 2005), e após a primeira exposição, geralmente ocorre imunização vitalícia, fato que ajuda a explicar a ocorrência mais freqüente de surtos de hepatite A em creches e escolas em relação a outros locais. A alta porcentagem de surtos causados por rotavírus em creches e escolas também pode ser explicada pelo mesmo princípio (imunidade após a primeira exposição ao vírus), sendo que nos EUA o pico dos surtos ocorre em crianças de 6 meses até 4 anos de idade. Entretanto, grandes inóculos do vírus ou baixa imunidade podem provocar doenças brandas em crianças mais velhas ou adultos (JAY, 2005).

Nos restaurantes, além da alta porcentagem de surtos em que o agente etiológico não foi identificado (58,8\%), merece destaque Salmonella sp. (responsável por 10,8\% dos surtos) e o grupo de microrganismos classificado como “outros” (26,7\%), composto por dezenas de espécies de microrganismos diferentes, majoritariamente bactérias (Fig. 5D).

Nas festas e buffet as bactérias Salmonella sp. e Staphylococcus coagulase + foram as maiores responsáveis, com 29,1\% e 7,8\% dos surtos, respectivamente (Fig. 5F). Também foi neste local de ocorrência onde Salmonella sp. causou a maior porcentagem de surtos em comparação com os outros locais. Apesar de proporcionalmente o número de surtos de Samonella sp. em festas e restaurantes ter sido maior, foi nas residências onde ocorreu o maior número deles, com 42 surtos notificados (Tab. 1). Nesta tabela também fica evidente a importância de Salmonella sp. nos surtos ocorridos em lanchonetes, onde essa bactéria participou em 26,2\% dos surtos, com 11 notificações.

A partir da constatação do grande número de surtos em festas envolvendo Salmonella sp. e Staphylococcus coagulase +, é possível fazer algumas considerações: no Brasil, ainda é muito comum o uso de ovos crus ou mal cozidos (fontes primárias de Salmonella) na preparação de maionese caseira e saladas para festas e eventos. Como também, a presença de Salmonella em altas taxas indica que o alimento foi preparado várias horas antes de ser consumido, permanecendo armazenado em temperatura ambiente ou refrigeração inadequada, favorecendo a rápida multiplicação bacteriana. A presença de Staphylococcus geralmente indica contaminação por manipuladores mediante condições higiênicas insuficientes, visto que esta bactéria tem a pele e as fossas nasais como seu habitat natural (JAY, 2005). Do mesmo modo, o preparo de alimentos várias horas antes do consumo e armazenamento à temperatura ambiente propicia ao Staphylococcus produzir altas concentrações de toxinas estafilocócicas, que são as responsáveis pelos sintomas da intoxicação alimentar por esta bactéria. 
Figura 5. Porcentagem de surtos notificados de DTAs no Estado de São Paulo entre 1995 e 2008 (excluído o ano 2007) segundo o agente etiológico (A) e segundo os mesmos agentes etiológicos nos cinco locais de ocorrência mais freqüentes (B; C; D; E; F) (dados de 1999 a 2008, excluído o ano 2007).

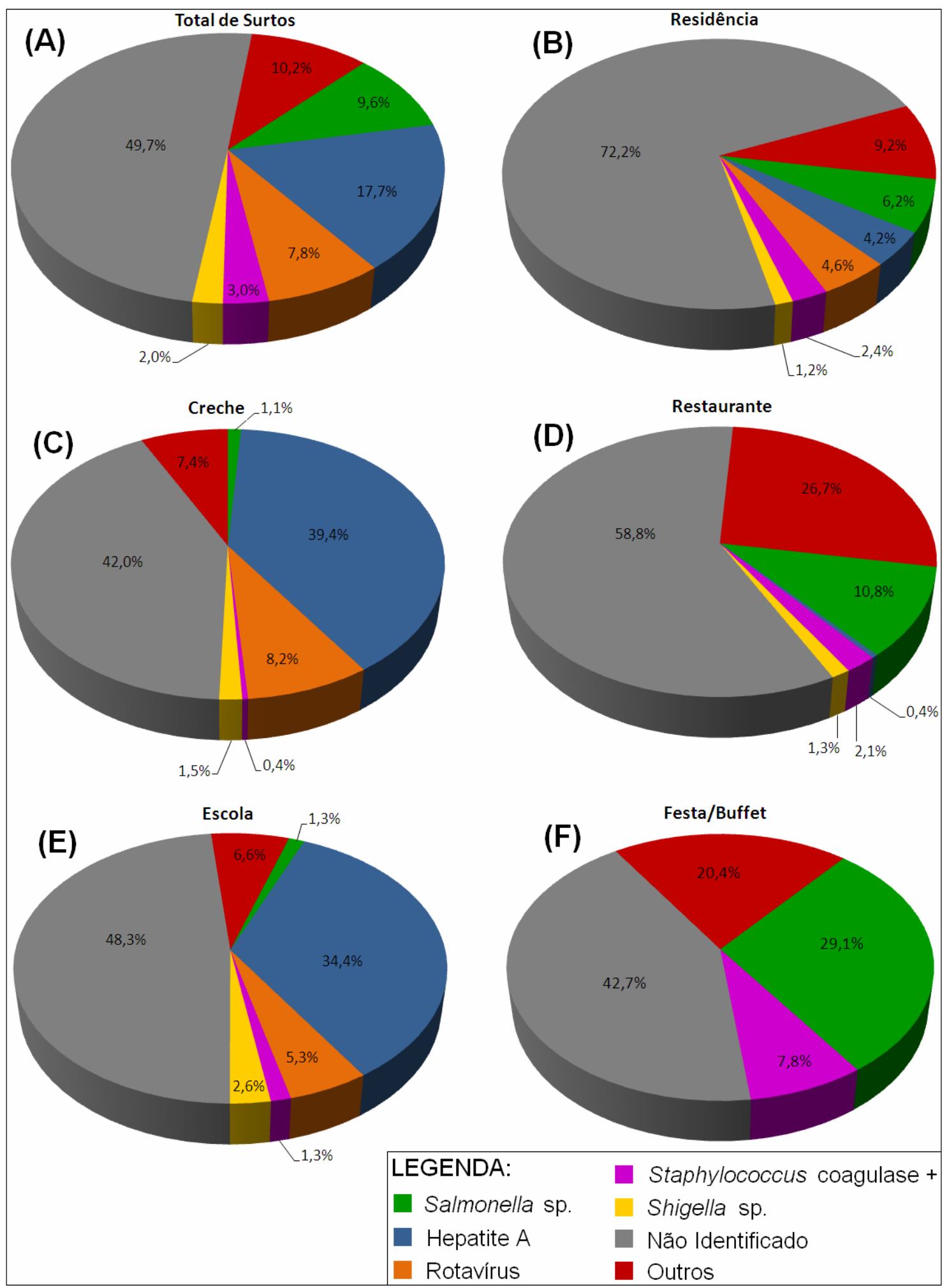

A Tabela 1 mostra ainda que depois das residências e das creches, os hospitais apresentaram o maior número de surtos (11) causados por rotavírus, sendo o microrganismo mais freqüentemente 
responsabilizado por esses surtos de DTAs em hospitais no Estado de São Paulo no período analisado.

Tabela 1. Número de surtos notificados de DTAs no Estado de São Paulo entre 1999 e 2008 (excluído o ano 2007) dos 10 locais de ocorrência mais freqüentes, distribuídos segundo o agente etiológico responsável.

\begin{tabular}{ccccccccc}
\hline Local de ocorrência & \multicolumn{7}{c}{ Agente Etiológico } \\
\cline { 2 - 9 } & A & B & C & D & E & NI & Outros & Total \\
\hline Residência & 42 & 28 & 31 & 16 & 8 & 486 & 62 & 673 \\
Creche & 3 & 106 & 22 & 1 & 4 & 113 & 20 & 276 \\
Restaurante & 26 & 1 & 0 & 5 & 3 & 141 & 64 & 240 \\
Escola & 2 & 52 & 8 & 2 & 4 & 73 & 10 & 152 \\
Festa & 30 & 0 & 0 & 8 & 0 & 44 & 21 & 103 \\
Empresa & 6 & 2 & 3 & 4 & 0 & 33 & 6 & 54 \\
Hospital & 4 & 1 & 14 & 1 & 1 & 23 & 5 & 49 \\
Refeitório & 5 & 0 & 0 & 3 & 1 & 24 & 12 & 45 \\
Lanchonete & 11 & 1 & 0 & 0 & 0 & 23 & 7 & 42 \\
Padaria & 4 & 0 & 0 & 6 & 0 & 19 & 5 & 34 \\
\hline A: Salmonella sp.; & & C: Rotavirus; & D: Staphylococcus coagulase +; & NI: Não Identificado.
\end{tabular}

Nestes 14 anos analisados, foram confirmadas 44 mortes decorrentes de doenças transmitidas por alimentos (Tab. 2). Destas, 34\% (15 óbitos) dos surtos ocorreram em residências e em 25\% (11 óbitos) o agente etiológico responsável pelo surto não foi identificado. Hepatite A causou 5 mortes e Clostridium botulinum 4 mortes. A Tabela 2 mostra ainda que das 8 mortes causadas por Salmonella sp. e S. enteritidis, metade delas foi devido ao uso de ovos e/ou maionese contaminados.

Tabela 2. Relação dos surtos notificados de DTAs no Estado de São Paulo entre 1995 e 2008 (excluído o ano 2007) que resultaram em mortes.

\begin{tabular}{cccccc}
\hline Agente etiológico & Alimento envolvido & Local de ocorrência & $\begin{array}{c}\text { Pessoas } \\
\text { expostas }\end{array}$ & $\begin{array}{c}\text { Pessoas } \\
\text { doentes }\end{array}$ & $\begin{array}{c}\text { Nr. de } \\
\text { óbitos }\end{array}$ \\
\hline & $\begin{array}{c}\text { Água, leite, iogurte, ovos, arroz, } \\
\text { molho de tomate } \\
\text { Intoxicação exógena; } \\
\text { rícino/mamona? }\end{array}$ & Residência & 2 & 2 & 2 \\
RI & Residência & 2 & 2 & 2 \\
Desconhecido & Residência & 6 & 6 & 1
\end{tabular}




\begin{tabular}{|c|c|c|c|c|c|}
\hline & $\mathrm{NI}$ & Festa & $\mathrm{NI}$ & 17 & 2 \\
\hline & NI & Instituição Def. Mental & NI & 60 & 2 \\
\hline & NI & Outro & 210 & 6 & 1 \\
\hline & NI & NI & NI & NI & 1 \\
\hline \multirow{5}{*}{ Hepatite A } & Pessoa-Pessoa & Residência & 2 & 2 & 1 \\
\hline & NI & Residência & 20 & 3 & 1 \\
\hline & NI & Creche & NI & 12 & 1 \\
\hline & NI & Creche & $\mathrm{NI}$ & 6 & 1 \\
\hline & NI & Bairro & NI & 20 & 1 \\
\hline \multirow[t]{3}{*}{ Rotavírus } & Pessoa-Pessoa & Internato & 10 & 10 & 1 \\
\hline & Pessoa-Pessoa & Residência & 6 & 6 & 1 \\
\hline & Torta de frango com palmito & Rotisserie & 1 & 1 & 1 \\
\hline Clostridium & Torta de frango e salgados & Rotisserie & 2 & 2 & 1 \\
\hline \multirow[t]{3}{*}{ botulinum } & Tofu em conserva importado da & Residência & 4 & 4 & 1 \\
\hline & China & & & & \\
\hline & NI & NA & 1 & 1 & 1 \\
\hline \multirow{3}{*}{$\begin{array}{l}\text { Clostridium } \\
\text { perfrigens }\end{array}$} & Frango & Festa & 32 & 20 & 1 \\
\hline & & & & & \\
\hline & Maionese caseira & Festa & 36 & 36 & 1 \\
\hline \multirow[t]{3}{*}{ Salmonella sp. } & Ovo, maionese & Lanchonete & 29 & 29 & 1 \\
\hline & Coxinha, bolinho de carne & Festa & 60 & 32 & 1 \\
\hline & NI & NI & $\mathrm{NI}$ & $\mathrm{NI}$ & 2 \\
\hline Salmonella & Maionese & Festa & 25 & 16 & 1 \\
\hline \multirow[t]{2}{*}{ enteritidis } & Salada de maionese & Difuso & 113 & 69 & 1 \\
\hline & $\mathrm{NI}$ & Mercearia & 8 & 8 & 1 \\
\hline Shigella sp. & $\mathrm{NI}$ & $\mathrm{NI}$ & $\mathrm{NI}$ & $\mathrm{NI}$ & 1 \\
\hline Shigella flexneri & NI & NI & $\mathrm{NI}$ & NI & 1 \\
\hline Shigella sonnei & Carne, arroz, feijão & Residência & 12 & 7 & 1 \\
\hline Coliformes fecais & Água & Reserva indígena & 145 & 24 & 2 \\
\hline E. coli $\mathrm{O} 128$ & NI & Município & 106 & 106 & 1 \\
\hline Febre Tifóide & Pessoa-Pessoa & Hospital & $\mathrm{NI}$ & 3 & 1 \\
\hline
\end{tabular}

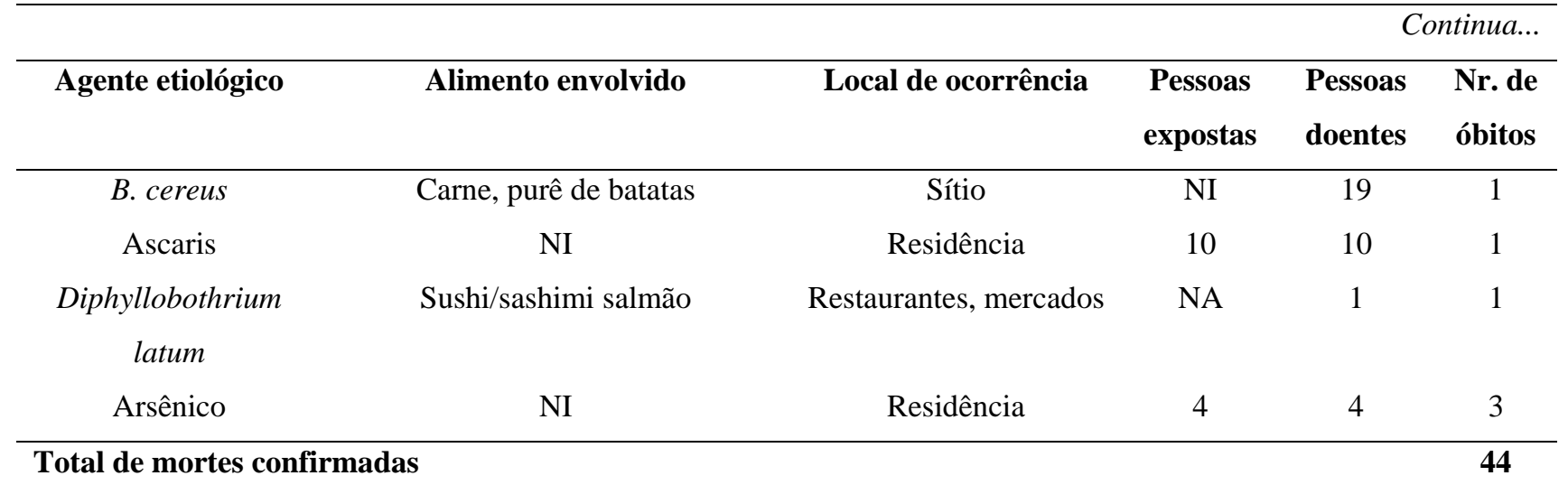

NA: Não se aplica. 
Em um estudo semelhante realizado no Estado do Paraná (AMSON et al., 2006), também constatou-se que a maioria dos surtos de DTAs ocorreu em residências (50,5\%), e que do total de surtos, Staphylococcus aureus e Salmonella sp. foram os agentes etiológicos mais freqüentes, correspondendo a 41,2\% e 33,8\% dos surtos, respectivamente. Neste estudo, que analisou dados de 1978 a 2000, também ficou evidente a participação de ovos e produtos de ovos nos surtos de salmonelose, principalmente na forma de maionese caseira.

Os três agentes etiológicos mais envolvidos com os surtos de DTAs em SP (vírus da hepatite A, Salmonella sp. e rotavírus) e que juntos corresponderam a 35,1\% dos surtos, mostraram ampla variação ao longo do período analisado (Fig. 6). Rotavírus mostrou uma incidência muito baixa nos cinco primeiros anos analisados, quando o número de surtos aumentou consideravelmente, partindo de 3 surtos em 1999 até alcançar o pico de 37 surtos em 2001. A partir deste mesmo ano o número de surtos por este vírus têm se mantido relativamente constante, com ligeiras quedas e aumentos destes. Apesar do número de surtos causados por Salmonella sp. também ter sido variável, estes encontram-se em declínio desde 2001, acumulando uma queda de 84\% desde aquele ano até 2008. Hepatite A teve seu pico no primeiro ano analisado (1995) com 124 surtos notificados. A partir daí o número baixou para apenas 16 casos em 1998 (redução de 87,1\%). Apesar do número de surtos por hepatite A ter baixado constantemente a partir de 2001, de 2006 a 2008 houve um aumento de 380\% no número de surtos, o que exige atenção por parte da população em geral e um monitoramento constante por parte do CVE-SP e órgãos correlatos como, por exemplo, a ANVISA (Agência Nacional de Vigilância Sanitária).

Figura 6. Variação do número de surtos notificados de DTAs no Estado de São Paulo entre 1995 e 2008 (excluído o ano 2007) segundo os três agentes etiológicos mais envolvidos.

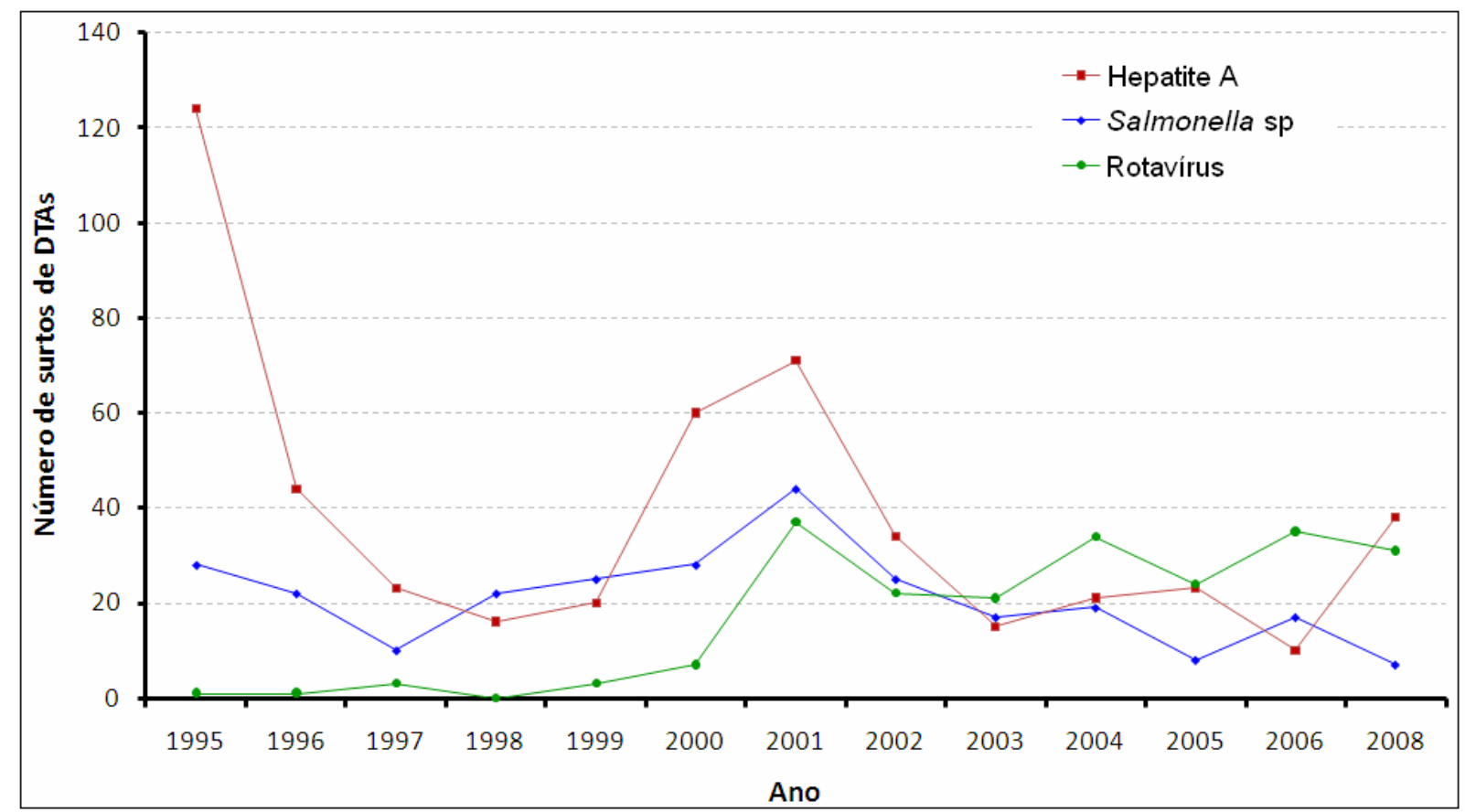


O uso de ovos crus ou mal cozidos no preparo de alimentos, principalmente maionese caseira e outras saladas, é uma importante fonte de salmonella sp., e este tipo de alimento é responsável por um grande número de surtos envolvendo esta bactéria no país (BRASIL, 2005). Para tentar diminuir este problema, em 1998 o governo de São Paulo decretou uma lei estadual proibindo o uso de maionese caseira em bares, restaurantes, lanchonetes, trailers e afins. Entretanto, esta lei é constantemente ignorada, como mostram as investigações de surtos de salmonelose após esta lei entrar em vigor, que muitas vezes identificaram a maionese caseira como o alimento responsável pela contaminação. Portanto, é necessária uma maior conscientização por parte da população e dos donos de estabelecimentos comerciais no sentido de abolir completamente o emprego de maionese caseira e ovos crus ou mal cozidos na preparação dos alimentos em geral.

A partir do ano 2000, os dados do CVE-SP também fornecem o número de comensais em cada surto, ou seja, o total de pessoas que ingeriram e/ou foram expostos ao microrganismo causador do surto, sendo que em muitos surtos este número não é absoluto, consistindo de uma estimativa aproximada, conforme as características inerentes a cada surto. Analisando-se o número de pessoas expostas em relação ao número de pessoas doentes (casos) segundo diferentes agentes etiológicos, encontrou-se que ampla variação (Fig. 7). Staphylococcus coagulase + foi o microrganismo que, proporcionalmente, deixou o maior número de comensais doentes $(17,54 \%)$, seguido por Salmonella sp. (9,9\%). Por outro lado, vírus da hepatite A e rotavírus (que estão entre os três agentes etiológicos mais freqüentemente responsabilizados pelos surtos) causaram doença em menos de $1 \%$ das pessoas expostas.

Figura 7. Porcentagem de pessoas doentes (casos) em relação ao número de pessoas expostas (comensais), segundo diversos agentes etiológicos nos surtos de DTAs notificados no Estado de São Paulo entre 2000 e 2008 (excluído o ano 2007).

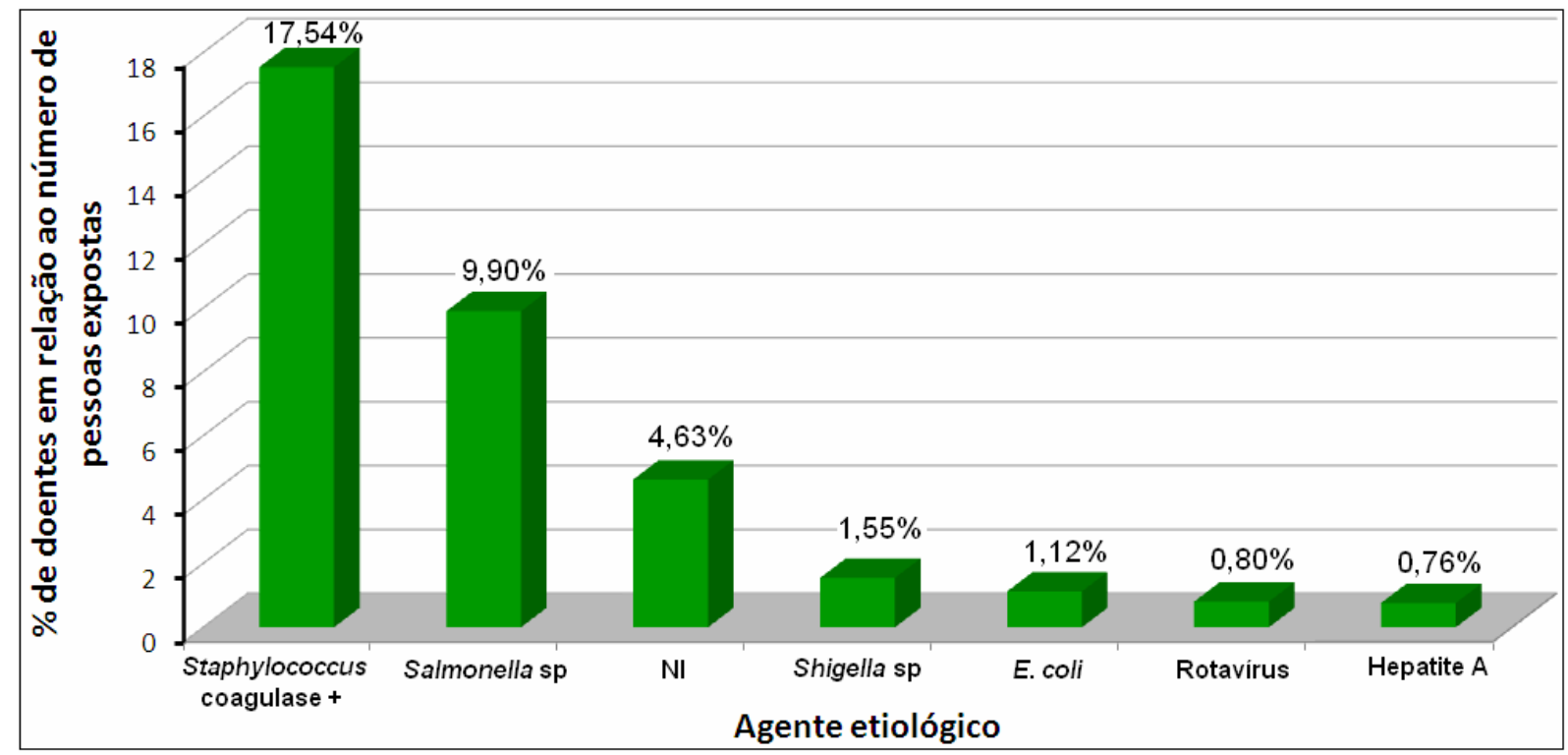

NI: Não Identificado. 
O baixo índice de pessoas doentes em relação ao número total de pessoas expostas nos surtos provocados por vírus, pode ser explicado pela imunidade adquirida pelo organismo após o primeiro contato com estes vírus (geralmente na infância), como já discutido acima. Rotavírus é de distribuição universal, e nos EUA é a principal causa de diarréia grave (SÃO PAULO, 2009). Apesar do baixo índice de pessoas doentes por rotavírus em relação ao número de pessoas expostas, o grande número de surtos no Brasil (principalmente em creches e escolas) demonstra que é necessário um controle mais rígido na qualidade da água de abastecimento. Por parte da população, é fundamental práticas higiênicas adequadas como lavagem das mãos, controle da qualidade da água e dos alimentos, além do destino adequado dos dejetos e do esgoto, que contaminados com o vírus, irão inevitavelmente contaminar o sistema de captação de água dos serviços de abastecimento. Ainda, o aleitamento materno parece ser de fundamental importância no combate ao vírus no organismo, pela transferência de anticorpos (SÃO PAULO, 2009).

Diante do fato de Salmonella sp. ser a bactéria mais freqüente em surtos de DTAs e que em boa parte deles a maionese caseira ser o alimento responsável, é pertinente a criação de uma lei federal no sentido de proibir o uso de maionese caseira em restaurantes, bares, lanchonetes, trailers, e afins, como fez o Estado de SP. Ainda, em função da maioria dos surtos ter ocorrido em residências e a falta de cuidados durante a preparação e do armazenamento dos alimentos (falta de higiene aliada à refrigeração inadequada) terem contribuído substancialmente para a ocorrência de grande número de surtos, também seria pertinente a criação de uma cartilha ilustrada com explicações detalhadas (escritas em uma linguagem simples) para distribuição para a população brasileira em geral.

\section{Conclusão}

A alta porcentagem de surtos de DTAs causados por bactérias em residências, restaurantes e festas envolvendo principalmente alimentos mistos como fonte da contaminação, indica que a falta de higiene dos manipuladores, no preparo dos alimentos várias horas antes do consumo, aliada à falta de refrigeração (ou refrigeração inadequada), juntamente com a contaminação cruzada, foram os maiores responsáveis pela ocorrência desses surtos.

Nas creches e escolas merece atenção o número de surtos causados por vírus (hepatite A e rotavírus) que somados foram responsáveis por praticamente metade dos surtos notificados nestes locais, evidenciando a necessidade de melhores políticas públicas no controle da qualidade da água e em medidas educativas referentes aos hábitos de higiene, principalmente por parte das crianças.

A queda no número de surtos provocados por Salmonella sp. a partir de 2001 sugere que há um conhecimento e cuidados maiores por parte da população em relação ao preparo e 
armazenamento dos alimentos, o que inclui evitar o uso de ovos crus ou mal cozidos no preparo destes (principalmente maionese caseira e saladas), uma vez que ovos são uma importante fonte de contaminação de Salmonella.

\title{
5. Agradecimentos
}

Os autores agradecem ao Centro de Vigilância Epidemiológica "Prof. Alexandre Vranjac" da Secretaria Estadual de Saúde do Estado de São Paulo (CVE-SP), pela permissão do uso de sua base de dados para a elaboração deste estudo e ao CNPq pelo suporte financeiro (bolsa de Doutorado).

\begin{abstract}
The consumption of foods and water contaminated with microorganisms or chemical substances can cause food-borne diseases. In this work were analyzed the notified food-borne diseases outbreaks in the State of São Paulo between 1995 and 2008 using it Center of Epidemic Surveillance database. The results showed that in this period 3,115 outbreaks were notified, with 99,689 sick and 44 deaths. The largest number of outbreaks happened in residences (28.2\%), daycares (11.6\%), restaurants (10.1\%), schools (6.4\%) and parties (4.3\%), and in $22.2 \%$ of the outbreaks the occurrence place was not identified. The mixed foods were the more involved (25\%), followed by the person-person contact (6.4\%), water (4.9\%), farinaceous (3.2\%), red meats (2.5\%), fish (2.3\%) and eggs and eggs products (1.9\%), and in $47 \%$ of the outbreaks the responsible food was not identified. In the daycares and schools hepatitis A virus and rotavirus were the microorganisms more involved, causing together $47.6 \%$ and $39.7 \%$ of the outbreaks, respectively. In the parties, restaurants and residences Salmonella sp. was the main microorganism, causing $29.1 \%, 10.8 \%$ and $6.2 \%$ of the outbreaks, respectively. Of the 44 confirmed deaths, $34 \%$ of the outbreaks happened in residences and in $25 \%$ of these outbreaks the etiological agent was not identified. Of the main involved microorganisms, Salmonella sp. showed the largest decline of the number of outbreaks starting from 2001, accumulating a reduction of $84 \%$ up to 2008, suggesting that the population is more conscious in relation to the cares in the food preparation and storage.
\end{abstract}

Key-words: foods; outbreaks; hepatitis A; Salmonella sp.; rotavirus.

\section{Referências}

AMSON, G.V.; HARACEMIV, S.M.C.; MASSON, M.L. Levantamento de dados epidemiológicos relativos à ocorrências/surtos de doenças transmitidas por alimentos (DTAs) no Estado do Paraná - Brasil, no período de 1978 a 2000. Ciência e Agrotecnologia, Lavras, v.30, n.6, p.1139-1145, 2006.

BRASIL. Ministério da Saúde. Secretaria de Vigilância em Saúde. Boletim eletrônico epidemiológico - vigilância epidemiológica de doenças transmitidas por alimentos no Brasil, 1999-2004, ano 5, n.06, 2005. Disponível em <http://www.saude.gov.br/svs $>$, acesso em 01/10/2009.

FORSYTHE, S. J. Microbiologia da segurança alimentar. $1^{\text {a }}$ edição. Porto Alegre: Artmed, 424p, 2000.

GERBA, C.P. \& GOYAL, S.M. Detection and occurrence of enteric viruses in shellfish: A review. Journal of Food Protection, v.41, p.743-754, 1978.

IBGE. Instituto Brasileiro de Geografia e Estatística. População recenseada e estimada, segundo os municípios - São Paulo - 2007. Disponível em <http://www.ibge.gov.br/home/estatistica/populacao/contagem2007>, acesso em $12 / 10 / 2009$. 
JAY, J.M.; trad. TONDO, E.C. et al. Microbiologia de Alimentos. 6 $6^{\text {a }}$ edição - Porto Alegre: Artmed, 2005.

MEAD, P.S.; SLUTSKER, L.; DIETZ, V.; MCCAIG, L.F.; BRESEE, J.S.; SHAPIRO, C.; GRIFFIN, P.M.; TAUXE, R.V. Food-related illness and death in the United States. Emerging Infectious Diseases, v.5, n.5, 1999.

RIO GRANDE DO SUL. Secretaria Estadual da Saúde. Centro Estadual de Vigilância em Saúde. Rede Estadual de Análise e Divulgação de Indicadores para a Saúde. A saúde da população do estado do Rio Grande do Sul. Porto Alegre: CEVS, 184p, 2006. Disponível em <http://www.saude.rs.gov.br/wsa/portal>, acesso em 24/05/2009.

SÃO PAULO. Secretaria Estadual de Saúde. Centro de Vigilância Epidemiológica. Equipe técnica da divisão de doenças de transmissão hídrica e Alimentar. Rotavírus: importante causa de surtos de diarréia em crianças menores de 5 anos - notifique! Disponível em < http://www.cve.saude.sp.gov.br/htm/hidrica/DTA_ROTVAG03.htm>, acesso em 10/10/2009.

UNITED STATES. Center for Disease Control and Prevention. Annual listing of foodborne disease outbreaks, United States, Disponível em <http://www.cdc.gov/foodborneoutbreaks/outbreak_data.htm>, acesso em 12/10/2009.

WHEELER, J.G.; SETHI, D.; COWDEN, J.M.; WALL, P.G.; RODRIGUES, L.C.; TOMPKINS, D.S.; HUDSON, M.J.; RODERICK, P.J. Study of infectious intestinal disease in England: rates in the community, presenting to general practice, and reported to national surveillance. British Medical Journal, v.318, p.1046-1050, 1999.

\section{DADOS COMPLETOS DOS AUTORES}

Nome completo : Laurí Mayer

Filiação institucional: Universidade Federal de Pelotas

Departamento: Departamento de Ciência e Tecnologia Agroindustrial

Função ou cargo ocupado: Bolsista Recém-Doutor - PRODOC/CAPES (Microbiologia Agroindustrial)

Titulação: Doutor em Ciências (Ciência e Tecnologia Agroindustrial (área: Microbiologia Agroindustrial))

Endereço completo para correspondência:

Laboratório de Microbiologia de Alimentos

Departamento de Ciência e Tecnologia Agroindustrial - FAEM

Universidade Federal de Pelotas

Campus Universitário - Pelotas/RS - Brasil

CEP. 96010-900 Caixa postal 354

Telefones para contato: (53) 3275-7258 ramal 202; Fax: (53) 3275-7258

e-mail: laurimayer@gmail.com

Nome completo : Wladimir Padilha da Silva

Filiação institucional: Universidade Federal de Pelotas

Departamento: Departamento de Ciência e Tecnologia de Alimentos

Função ou cargo ocupado: Professor Associado II

Titulação: Doutorado em Ciência dos Alimentos - USP

Endereço completo para correspondência:

Laboratório de Microbiologia de Alimentos

Departamento de Ciência e Tecnologia Agroindustrial - FAEM

Universidade Federal de Pelotas

Campus Universitário - Pelotas/RS - Brasil 
CEP. 96010-900 Caixa postal 354

Telefones para contato: (53) 3275-7258 ramal 203

e-mail:silvawp@ufpel.edu.br 